\title{
Viral contamination in biologic manufacture and implications for emerging therapies
}

\author{
Paul W. Barone', Michael E. Wiebe', James C. Leung', Islam T. M. Hussein', Flora J. Keumurian', \\ James Bouressa ${ }^{2,25}$, Audrey Brussel ${ }^{3,26}$, Dayue Chen ${ }^{4,27}$, Ming Chong5, Houman Dehghani ${ }^{6,28}$, \\ Lionel Gerentes ${ }^{7}$, James Gilbert ${ }^{8,29}$, Dan Gold ${ }^{9}$, Robert Kiss ${ }^{10,30}$, Thomas R. Kreil ${ }^{11}$, René Labatut ${ }^{3}$, \\ Yuling Li ${ }^{12,31}$, Jürgen Müllberg ${ }^{13}$, Laurent Mallet ${ }^{7,32}$, Christian Menzel ${ }^{14}$, Mark Moody ${ }^{15,33}$, \\ Serge Monpoeho ${ }^{16}$, Marie Murphy4 ${ }^{4}$ Mark Plavsic ${ }^{17,34}$, Nathan J. Roth ${ }^{18}$, David Roush" \\ Michael Ruffing ${ }^{20}$, Richard Schicho ${ }^{21,35}$, Richard Snyder ${ }^{22}$, Daniel Stark ${ }^{23}$, Chun Zhang ${ }^{24,36}$, \\ Jacqueline Wolfrum', Anthony J. Sinskey ${ }^{1}$ and Stacy L. Springs ${ }^{1}{ }^{1}$
}

Recombinant protein therapeutics, vaccines, and plasma products have a long record of safety. However, the use of cell culture to produce recombinant proteins is still susceptible to contamination with viruses. These contaminations cost millions of dollars to recover from, can lead to patients not receiving therapies, and are very rare, which makes learning from past events difficult. A consortium of biotech companies, together with the Massachusetts Institute of Technology, has convened to collect data on these events. This industry-wide study provides insights into the most common viral contaminants, the source of those contaminants, the cell lines affected, corrective actions, as well as the impact of such events. These results have implications for the safe and effective production of not just current products, but also emerging cell and gene therapies which have shown much therapeutic promise.

\begin{abstract}
$\mathrm{n}$ the twentieth century, several vaccine products were unintentionally contaminated with unwanted viruses during their production ${ }^{1-3}$. This included the contamination of poliovirus vaccine with simian virus $40(\mathrm{SV} 40)^{3}$, for which the health impacts were not fully known for many decades ${ }^{4}$. In the early 1980s, unknowingly contaminated therapeutic proteins from human plasma caused widespread transmission of viruses such as human immunodeficiency virus (HIV) to people with hemophilia who received these treatments ${ }^{5,6}$. As a result, public trust in the plasma industry's ability to safely make these therapies declined ${ }^{7,8}$. To ensure that current plasma-derived, vaccine, and recombinant biotherapeutics are safe, complementary safety strategies to reduce the risk of virus contamination were developed and implemented ${ }^{9-11}$.

Since that time, the production of therapeutic proteins has largely shifted to the use of recombinant DNA technology in prokaryotic and eukaryotic cells ${ }^{12}$. However, culturing of these cells is susceptible to contamination from adventitious agents (primarily bacteria and viruses). Viruses are of particular concern as they are often more difficult to detect than other microbial contaminants ${ }^{1}$ and in the case of mammlian cell culture can potentially replicate
\end{abstract}

human pathogens. The lessons of the past have led to the current best practice, which relies on three pillars: the selection of appropriate starting and raw materials with a low risk of containing adventitious virus; testing of cell banks and in-process materials to ensure they are free from detectable viruses; and finally, the incorporation of steps to remove and inactivate potential undetected adventitious and endogenous viral contaminants during purification of the product $^{9,13,14}$. Because of this approach, these products have been safe for over 35 years, and, to our knowledge, there has been no transmission of a contaminating virus to a patient from a therapeutic protein produced using recombinant DNA technology.

Despite this excellent safety record, viral infection of mammalian cell culture is a real risk with severe consequences. Even if no contaminated lots are released, patients who require treatment can be affected by drug shortages and public confidence in the biotech industry can be severely damaged. These events can cost tens of millions of dollars in investigation, cleanup, corrective actions, lost sales and manufacturing plant downtime ${ }^{15}$. They also divert company leadership, encourage the competition, and can decrease company value. Finally, they expose the company

\footnotetext{
${ }^{1}$ Center for Biomedical Innovation, Massachusetts Institute of Technology, Cambridge, MA, USA. ${ }^{2}$ Pfizer Inc., Andover, MA, USA. ${ }^{3}$ Sanofi, Paris, France. ${ }^{4}$ Eli Lilly, Indianapolis, IN, USA. ${ }^{5}$ CSL Behring, Melbourne, Victoria, Australia. ${ }^{6}$ Amgen, Thousand Oaks, CA, USA. ${ }^{7}$ Sanofi Pasteur, Marcy L'Étoile, France. ${ }^{8}$ Biogen Inc., Cambridge, MA, USA. ${ }^{9}$ BioMarin, San Raphael, CA, USA. ${ }^{10} \mathrm{Genentech,} \mathrm{South} \mathrm{San} \mathrm{Francisco,} \mathrm{CA,} \mathrm{USA.} \mathrm{"Baxter/Baxalta/Shire,} \mathrm{now} \mathrm{part}$ of Takeda, Vienna, Austria. ${ }^{12}$ Medlmmune, Gaithersburg, MD, USA. ${ }^{13}$ Bristol-Myers Squibb, Devens, MA, USA. ${ }^{14}$ Merck Group, Geneva, Switzerland. ${ }^{15}$ Merrimack Pharmaceuticals, Cambridge, MA, USA. ${ }^{16}$ Regeneron, Rensselaer, NY, USA. ${ }^{17}$ Sanofi Genzyme, Cambridge, MA, USA. ${ }^{18} \mathrm{CSL}$ Behring, Bern, Switzerland. ${ }^{19}$ Merck \& Co., Inc., Kenilworth, NJ, USA. ${ }^{20}$ Boehringer Ingelheim, Biberach, Germany. ${ }^{21}$ Bristol-Myers Squibb, New York, NY, USA. ${ }^{22}$ Brammer Bio, Alachua, FL, USA. ${ }^{23}$ Novartis, Basel, Switzerland. ${ }^{24}$ Shire, Lexington, MA, USA. ${ }^{25}$ Present address: Retired, Andover, MA, USA. ${ }^{26}$ Present address: LFB, Les Ulis, France. ${ }^{27}$ Present address: Genentech, South San Francisco, CA, USA. ${ }^{28}$ Present address: Allogene Therapeutics, South San Francisco, CA, USA. ${ }^{29}$ Present address: Independent consultant, Westcliffe, CO, USA. ${ }^{30}$ Present address: Sutro Biopharma Inc., South San Francisco, CA, USA. ${ }^{31}$ Present address: Innoforce, Hangzhou, Zhejiang, China. ${ }^{32}$ Present address: EDQM, Strasbourg, France. ${ }^{33}$ Present address: Immunova, Cambridge, MA, USA. ${ }^{34}$ Present address: Lysogene, Cambridge, MA, USA. ${ }^{35}$ Present address: Shire, Atlanta, GA, USA. ${ }^{36}$ Present address: Evelo Biosciences, Cambridge, MA, USA. 凶e-mail: ssprings@mit.edu
} 
Table 1 | Virus contaminations of mammalian cell culture to produce proteins and vaccines, segregated by year, both publicly reported and contained in the CAACB study

\begin{tabular}{|c|c|c|}
\hline $\begin{array}{l}\text { Year of } \\
\text { contamination }\end{array}$ & Contaminations (virus / host cell) & Total \\
\hline 1985-1989 & $\begin{array}{l}\text { Blue tongue / } \mathrm{CHO} \\
\text { EHDV / CHO }\end{array}$ & 2 \\
\hline 1990-1994 & $\begin{array}{l}\text { Herpesvirus / primary monkey } \\
\text { Herpesvirus / Vero } \\
\text { MVM / CHO }(\times 2)^{20-22} \\
\text { Parainfluenza 3 / MRC5 } \\
\text { Reo3 / MRC5 } \\
\text { Simian adenovirus / primary monkey }\end{array}$ & 7 \\
\hline 1995-1999 & $\begin{array}{l}\mathrm{CVV} / \mathrm{CHO} \\
\text { Reovirus / human primary kidney }{ }^{23} \\
\text { Vesivirus } 2117 / \mathrm{CHO}^{24}\end{array}$ & 3 \\
\hline $2000-2004$ & $\begin{array}{l}\text { CVV / unknown }(\times 2)^{25} \\
\text { Human adenovirus / HEK29326 }\end{array}$ & 3 \\
\hline 2005-2010 & $\begin{array}{l}\mathrm{CVV} / \mathrm{CHO} \\
\mathrm{MVM} / \mathrm{CHO}(\times 2) \\
\text { Vesivirus } 2117 / \mathrm{CHO}(\times 3)^{27-29}\end{array}$ & 6 \\
\hline 2010-present & $\begin{array}{l}\text { MVM / } \mathrm{CHO}^{30} \\
\text { MVM / BHK-21 } \\
\text { PCV-1 / Vero }\end{array}$ & 3 \\
\hline Unknown & $\begin{array}{l}\text { MVM / BHK-2133 } \\
\text { Reovirus / Unknown }{ }^{34}\end{array}$ & 2 \\
\hline
\end{tabular}

Contaminating virus and host cell line are indicated where known. Note: some contamination events were reported publicly and in more detail to the CAACB. CVV, Cache Valley virus; EHDV, epizootic hemorrhagic disease virus; $M V M$, minute virus of mice; $P C V-1$, porcine circovirus type 1 ; Reo3, reovirus type 3 .

to intense regulatory scrutiny and can result in a delay in the approval of new products or the accelerated approval of a competitor's product ${ }^{16,17}$.

Despite the above damaging consequences from virus contamination, effectively learning from previous contamination events is a challenge. These events are rare; we are aware of only 26 virus contaminations over the past 36 years (Table 1) ${ }^{18-35}, 18$ of which were reported directly as a part of this study. Furthermore, a comprehensive dataset and evaluation of virus contaminations in biomanufacturing has not previously been published. Therefore, the Consortium on Adventitious Agent Contamination in Biomanufacturing (CAACB) - a biopharmaceutical industry consortium including more than 20 biotechnology companies housed at the Massachusetts Institute of Technology's Center for Biomedical Innovation-collected comprehensive data on virus contaminations in cell culture operations from CAACB member companies ${ }^{36}$. These data were consolidated with information from published reports of virus contamination events. To our knowledge, this is the only comprehensive dataset available on adventitious virus contaminations of mammalian cell culture in the biotech industry. This industry-wide study is the first of its kind and provides insights into the most common viral contaminants, the source of those contaminants, the cell lines affected, corrective actions taken, and the impacts of such events.

In this Perspective, we describe the work to date and discuss the implications of our findings for manufacturers of recombinant protein therapies. We then use these insights to outline viral contamination considerations for developers of emerging gene and cell therapies. Our aim in this paper is to facilitate the industry's mission of producing safe and effective biologic products. We note that this is a living project and that we expect to continually collect and analyze data in the future.
The CAACB virus contamination in biomanufacturing study To date, the CAACB has collected a comprehensive set of data on virus contamination experience, as well as controls in place to prevent contaminations, from 20 major biopharmaceutical manufacturers. A 166-question survey of the CAACB members was used to conduct the study (see Supplementary Note). To ensure a manageable dataset for comparable processes, the scope of the project was limited to virus contaminations in mammalian cell culture manufacturing. The project did not include bacterial or yeast fermentation, plasma fractionation or egg-based production of vaccines and covered manufacturing from the pilot to commercial scales, including both current Good Manufacturing Practice (cGMP) and non-cGMP operations. Unless otherwise noted, all data and discussion here relates to information reported directly to the CAACB and does not include information from other published reports.

Nine out of the 20 responding companies (or almost half of the involved industry respondents) reported having one or more adventitious virus contaminations in mammalian cell culture operations since 1985 , totaling 18 virus contamination events reported to the CAACB. All of these reported contamination events occurred at manufacturing sites in North America and Europe, but there is insufficient data to determine whether one geographic location has a disproportionately increased risk of contamination over another.

Different host cells, different risks. The contaminated cell type, contaminating virus and suspected source of contamination for the 18 events reported to the CAACB are shown in Table 2. In $67 \%$ of reported events, the manufacturing platform was Chinese hamster ovary (CHO) cells, whereas the other $33 \%$ of events involved human or primate cell lines. This result is not unexpected as $\mathrm{CHO}$ cells are the most commonly used host cells by the recombinant-biologic industry, with published reports indicating that approximately $70 \%$ of approved biotech products are manufactured using $\mathrm{CHO}$ cells ${ }^{12}$. The reported virus contaminations occurred at all stages of the product life cycle, with 3 events occurring during preclinical non-cGMP manufacture, 2 during clinical cGMP manufacture, and the remaining 13 occurring during commercial manufacture. Considering the strict controls in place for clinical and commercial manufacturing, the fact that most contaminations reported to the CAACB occurred under cGMP production may be surprising. One possible explanation is that the scale of cGMP production and volumes of media used were much greater than those of non-cGMP production, allowing a greater opportunity to introduce a low-level contaminant. Additionally, viral testing is not mandatory for non-cGMP manufacturing and some contamination events may not have been recognized. All of the commonly used cell culture processes in the industry, such as roller bottle (one event), batch culture (three events), fed-batch culture (four events) and perfusion culture (four events), were implicated. In six events, the type of cell culture process was not identified by respondents. On the basis of the available data, it is not possible to determine whether one operational mode has a higher risk of contamination than another.

Nine viral contaminants have been identified as responsible for the 18 virus contamination events reported to the CAACB (Table 2). No overlap exists between the four viruses found to contaminate $\mathrm{CHO}$ cell culture and the five viruses found to contaminate human or primate cells. This highlights the fact that the contamination and safety risks are distinct for $\mathrm{CHO}$ cells versus human or primate cells. In 11 of the 12 reported contaminations in $\mathrm{CHO}$ cell culture, a raw material or medium component was identified or suspected to be the source. In comparison, for the human and primate cell lines, the manufacturing operators or cell line itself were suspected to be the source. The fact that operators are only indicated as a source of the contaminant in human or primate cell culture and not in $\mathrm{CHO}$ cell culture is likely due to the 'species barrier' for viral infection between human or primate cells on the one hand and rodent cells on the other. 
Table 2 | Viruses reported to have contaminated mammalian cell culture operations for the production of vaccines or recombinant proteins, the number of events where the virus source was identified, and the source of the contaminant

\begin{tabular}{|c|c|c|c|c|c|c|c|c|}
\hline \multirow{2}{*}{$\begin{array}{l}\text { Contaminated } \\
\text { cell line }\end{array}$} & \multirow[t]{2}{*}{ Contaminating virus } & \multirow{2}{*}{$\begin{array}{l}\text { Pathogenic } \\
\text { to humans }\end{array}$} & \multicolumn{6}{|c|}{ Suspected and confirmed sources of contamination } \\
\hline & & & Serum & $\begin{array}{l}\text { Recombinant } \\
\text { medium component }\end{array}$ & $\begin{array}{l}\text { Undetermined } \\
\text { medium component }\end{array}$ & Operator & $\begin{array}{l}\text { Host } \\
\text { cell line }\end{array}$ & $\begin{array}{l}\text { Not } \\
\text { found }\end{array}$ \\
\hline \multicolumn{9}{|c|}{ Viruses found to contaminate $\mathrm{CHO}$ cell culture } \\
\hline $\mathrm{CHO}$ & Blue tongue virus & No & 1 & & & & & \\
\hline $\mathrm{CHO}$ & Cache Valley virus & Yes & 2 & & & & & \\
\hline $\mathrm{CHO}$ & Minute virus of mice & No & & 1 & 3 & & & 1 \\
\hline $\mathrm{CHO}$ & Vesivirus 2117 & No & 4 & & & & & \\
\hline \multicolumn{9}{|c|}{ Viruses found to contaminate human or primate cell lines } \\
\hline $\begin{array}{l}\text { Primary monkey, } \\
\text { Vero }\end{array}$ & Herpesvirus & Yes & & & & 1 & 1 & \\
\hline HEK293 & $\begin{array}{l}\text { Human adenovirus } \\
\text { type } 1\end{array}$ & Yes & & & & 1 & & \\
\hline MRC5 & $\begin{array}{l}\text { Parainfluenza virus } \\
\text { type } 3\end{array}$ & Yes & & & & 1 & & \\
\hline MRC5 & Reovirus type 3 & Yes & & & & 1 & & \\
\hline Primary monkey & Simian adenovirus & No & & & & & 1 & \\
\hline
\end{tabular}

Simply put, viruses that infect humans are more likely to be able to replicate in human cells than in non-human mammalian cells.

Safety implications. Four (herpesvirus, human adenovirus type 1, parainfluenza virus type 3 and reovirus type 3 ) of the five viruses found to contaminate human and primate cell lines are known to be pathogenic in humans, whereas only one (Cache Valley virus) of the viruses found to contaminate $\mathrm{CHO}$ cell culture has been reported to cause disease in humans ${ }^{37,38}$. These data highlight that the viral contamination of protein products produced in human or primate cell lines pose a higher safety risk to patients and the manufacturing process due to human cell line susceptibility to infection by viruses that are pathogenic in humans.

Animal-derived raw materials (ADRMs), especially serum, carry a higher risk of being contaminated with virus and are thus being replaced where possible throughout the industry ${ }^{1,9,13}$. This is further corroborated by our data: three (blue tongue virus, Cache Valley virus and vesivirus 2117) of the four viruses that contaminated $\mathrm{CHO}$ cell culture were suspected or definitively identified to have come from serum. However, the removal of ADRMs does not eliminate the risk of contamination. In one contamination with the minute virus of mice (MVM), the process contained no ADRMs. Minute virus of mice is especially challenging as a potential contaminant. It is shed from ever-present wild mouse populations, may not be detectable even with established rodent control, and can persist in the environment and in raw materials long after being shed.

Despite the fact that raw materials were determined to be the most likely source of the contamination in 11 events, testing those raw materials did not necessarily detect the contaminating virus. In only 3 events was the viral contaminant directly detected in the suspect raw material (Fig. 1). In all 3 cases, it was necessary to increase the viral load to a level detectable by PCR through either amplification by virus replication in cell culture or concentration of the raw material. In the other 8 contamination events, virus testing of raw materials was negative and the source of the contamination was only identified using indirect evidence.

\section{Virus detection methods}

As viruses are obligate molecular parasites that co-opt the cellular machinery of the host cell they infect, it might be expected

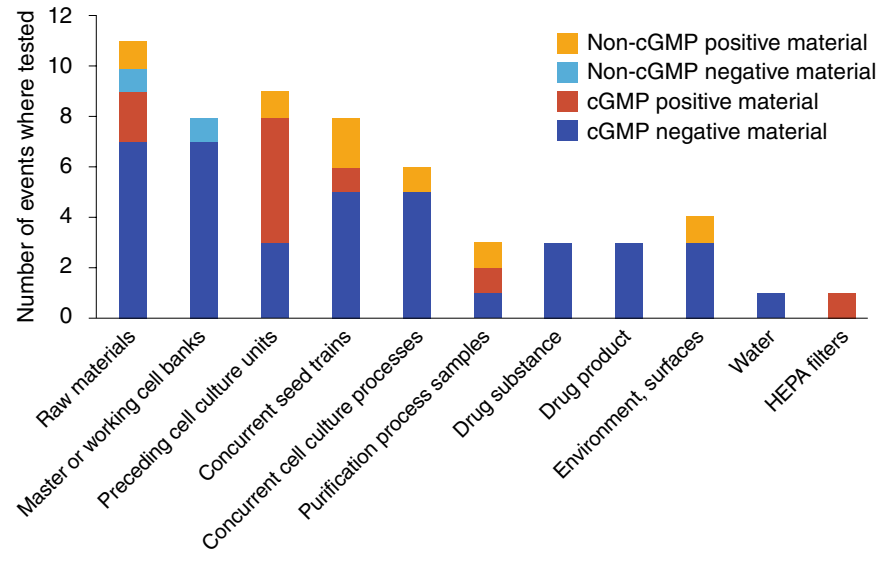

Fig. 1 | Virus testing of contaminated processes. Virus tests on samples from different process steps of the affected runs during investigation of the contamination events reported to the CAACB. Data reported to the CAACB included samples from cGMP operations that tested positive (dark orange) or that were below the limit of detection of the assay and assumed negative (dark blue) and samples from non-cGMP operations that tested positive (light orange) or that were below the limit of detection of the assay and assumed negative (light blue). Note: not all materials were tested in each contamination event.

that their contamination of mammalian cell culture would lead to obvious changes in culture performance parameters (for example, viable cell density). For 11 of the 18 contamination events reported to the $\mathrm{CAACB}$, a change in cell culture parameters was the leading indicator of a contamination ( 5 of 18 events occurred sufficiently long ago that it is not known whether there was a change in cell culture parameters). However, in 2 events, there was no apparent change in cell culture performance and the contaminating virus was only detected by a virus-specific PCR assay. This suggests that cell culture performance alone may not provide sufficient warning of contamination. Additionally, changes to cell culture performance can be due to many factors other than virus contamination. 
Table 3 | Methods used for the detection (both initial detection and confirmation of a contamination) and identification of the viral contaminant of a virus contamination in cell culture operations

\begin{tabular}{|c|c|c|c|c|c|}
\hline \multirow[t]{2}{*}{ Methods } & \multirow[t]{2}{*}{ Detection } & \multirow{2}{*}{$\begin{array}{c}\text { Virus } \\
\text { identification }\end{array}$} & \multicolumn{3}{|c|}{ Used for QC lot release assay } \\
\hline & & & Used for QC test & QC test positive & QC test negative \\
\hline PCR & 8 & 11 & $1^{\mathrm{a}}$ & 1 & 0 \\
\hline IVV test & 7 & & 14 & $11^{\mathrm{b}}$ & $4^{\mathrm{b}}$ \\
\hline Electron microscopy & 4 & 3 & & & \\
\hline Viral genome sequencing & & 3 & & & \\
\hline Immunofluorescence & 2 & 2 & & & \\
\hline Mass spectrometry protein sequencing & & 2 & & & \\
\hline RNA fingerprinting & 1 & 1 & & & \\
\hline Serology & & 6 & & & \\
\hline Massively parallel sequencing & 1 & 1 & & & \\
\hline
\end{tabular}

The number of contamination events where each test was used is listed in each column; multiple tests may have been used in each event. Tests used for QC lot release, and whether they were positive or negative, are indicated. ${ }^{\circ}$ One company used both PCR and IVV tests for QC lot release; in one event, PCR was positive, but the IVV test was negative. ${ }^{b}$ One company found some bioreactors to be positive by PCR but negative by IVV test, whereas other bioreactors were positive by both tests. This is counted in both columns.

The in vitro virus (IVV) assay is a cell-based assay used to test cell culture harvest samples for potential viral contaminants ${ }^{39}$. It is able to detect a wide range of viruses and was used as a quality control (QC) lot release assay in all 15 events that were carried out under cGMP manufacturing. Despite this, the IVV assay was negative in 4 events and the contamination was detected by using another method (Table 3). These data imply that the safety of biologic products should not rely on testing alone (including orthogonal methods) but be assured by multiple controls (including prevention, detection and viral clearance) throughout the process.

Whereas the data in Table 3 highlight the deficiencies of a range of widely used detection assays, the use of rapid virus detection assays has prevented the spread of a viral contaminant throughout a production facility. Of the 18 contamination events reported to the CAACB, 7 were contained in cell culture bioreactors (Fig. 2). Noteworthy is the fact that in 3 of the events, virus-specific PCR tests performed before bioreactor harvest detected and identified a viral contaminant in the bioreactor and prevented the spread of the virus to downstream purification processes and other parts of the manufacturing facility. This greatly reduced the time, effort and cost of both investigating the event and getting the manufacturing facility back up and running. Conversely, no rapid PCR assays were in place in the 6 events in which contaminated cell culture fluid was processed downstream. As PCR assays are designed for a specific target virus or panel of viruses, a viral contamination will only be detected if primers and probes for the contaminating virus are included in the assay. However, these data highlight the capability of rapid detection assays to reduce business risk and increase product safety, especially in known high-impact situations.

\section{Current viral safety approaches work}

Data collected as a part of the CAACB study indicate that current manufacturing controls used to prevent the spread of a potential contaminant within manufacturing facilities are effective as no cross-contamination of other concurrent manufacturing operations was reported. Figure 1 shows the results for in-process materials that were tested for virus during the post-contamination investigation. For cGMP production, five of eight cell cultures preceding the reactor were originally identified as contaminated; one of six concurrent seed trains and no concurrent cell cultures for different products were also found to be contaminated. In all cases, the contamination of concurrent cell culture operations came from a shared raw material and not from cross-contamination within the manufacturing facility. This supports the effectiveness of cross-contamination controls currently in place. Although outside the scope of this work, a comprehensive discussion of biomanufacturing controls to prevent cross-contamination can be found in the ISPE Baseline Guide Volume 6: Biopharmaceutical Manufacturing Facilities ${ }^{40}$. It should be noted that, in one contamination event, high-efficiency particle absorbing (HEPA) filters tested positive for the contaminating virus. Whereas some may consider the likelihood of virus being aerosolized in a manufacturing setting to be low, this highlights the fact that it is not impossible-the $0.2-\mu \mathrm{m}$ vent filters on bioreactors are not designed to retain virus - and manufacturing facility design and decontamination activities in the event of a contamination should take this into account (for example, using a decontamination approach proven to be virucidal and capable of reaching areas potentially exposed to aerosols).

Data reported to the CAACB also support the effectiveness of the virus removal and inactivation capacity of downstream purification operations, which has been documented elsewhere ${ }^{41,42}$. As an assurance of safety, the unit operations of the downstream purification process, such as chromatography, are evaluated at small scale for their ability to separate potential viral contaminants from the final product. Dedicated steps to inactivate virus (for example, a low-pH hold or solvent or detergent treatment for large, enveloped viruses) and remove virus (for example, the use of nanofiltration) are also designed into downstream purification. These processes are evaluated for their ability to clear model adventitious viruses with a range of biochemical and biophysical properties. As these studies are not designed to evaluate a specific safety risk, there is no minimum clearance suggested in the guidance 9 . In four of the six contaminations that spread downstream, the capacity of the large-scale purification steps to clear virus was evaluated (Fig. 2). Whereas some purification process intermediates tested positive for virus (Fig. 1), in all cases, the entire purification process reduced the contaminating virus to levels below the limit of detection of the assay. Where tested, all drug substance and drug product tested negative for virus. Additionally, for all six contaminations that spread to downstream processes, no virus testing (for example, PCR) of bioreactors, with a negative result required to further process the cell culture harvest, had been implemented. It is important to note that in all cases reported to the $\mathrm{CAACB}$, no drug substance produced from a contaminated cell culture was ever released for human use, and all such drug substances were subsequently destroyed.

Without a doubt, an adventitious virus contamination during cell culture manufacture of a biologic is incredibly disruptive. Investigating a viral contamination event costs both time and 

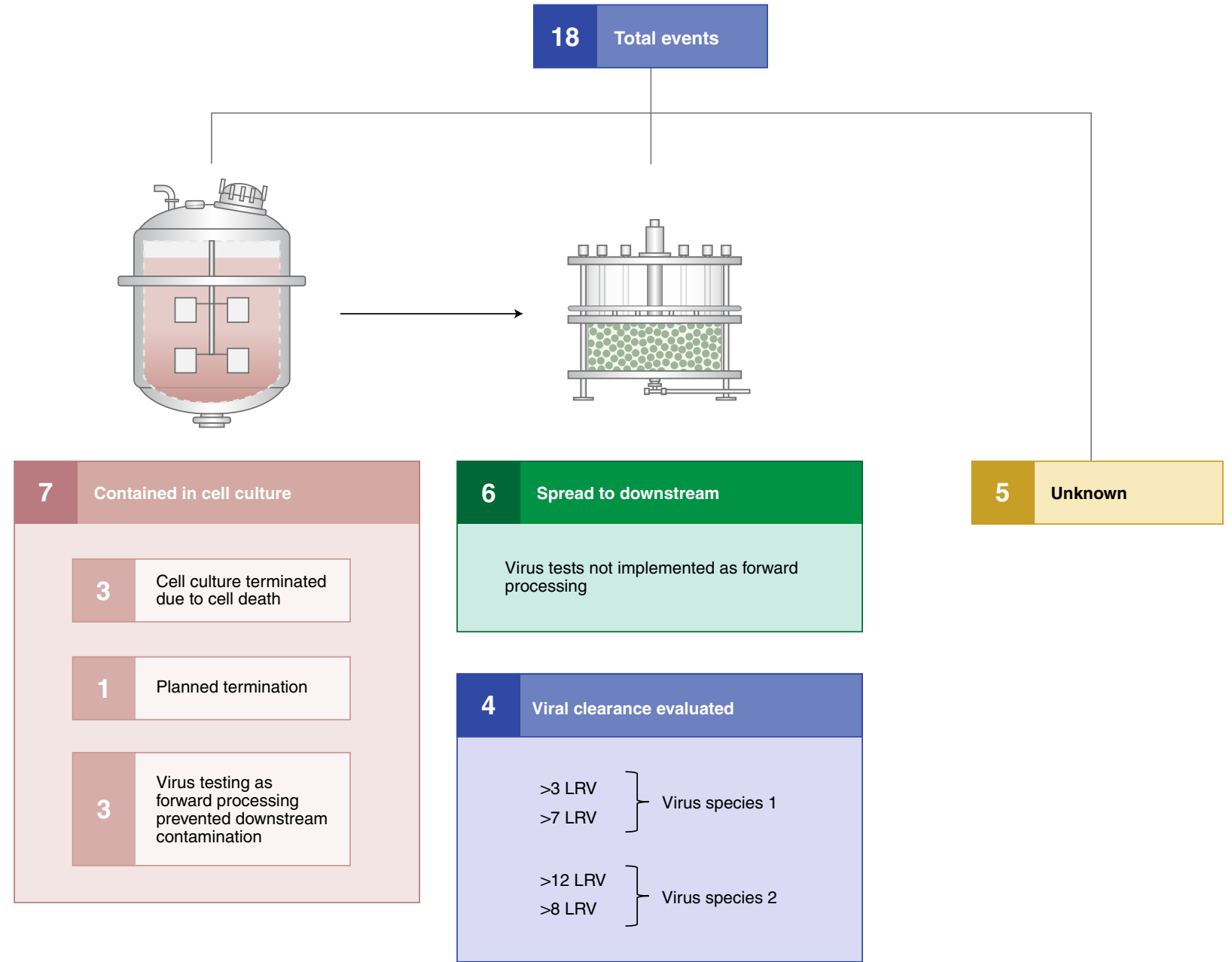

Fig. 2 | Extent of contamination. Schematic showing the extent of contamination in the manufacturing process and the use of virus detection as a process forwarding criteria. For seven events, the contamination was contained in the cell culture, for six events the contamination was spread to downstream purification operations, and for five events the extent of contamination was unknown. The ability of the downstream process to remove or inactivate the viral contaminant was evaluated in four of the six contamination events and was found to remove contaminating virus below the limit of detection of the assay. For all six contaminations that spread to downstream processes, no virus testing was implemented as process forwarding criteria. LRV stands for log reduction value and is a measure of the ability of the process to remove or inactivate virus. As an example, a process that is capable of reducing the viral load by a factor of $10^{4}$, such as from a viral titer of $10^{10}$ to a titer of $10^{6}$, is said to have a LRV of 4 .

resources. Depending on the severity of the event, the investigation could take several months for personnel involved. The expense of such an investigation, as reported to the CAACB, was in the \$1-10 million range, but in the worst cases the cost of investigating a contamination, implementing corrective actions, decontaminating the facility, and other ancillary costs could be in the hundreds of millions of dollars. In multiple events reported to the CAACB, the contamination resulted in a competitive disadvantage to some products. Furthermore, viral contaminations have been reported to lead to manufacturing interruptions (with a median plant downtime of 1 to 2 months; Fig. 3), loss of revenue, discarded batches, lawsuits against the company, a decrease in company reputation as reflected in stock value, and significant delays in product development. Finally, these events can affect patients. In one event, the negative impact on drug supply resulted in a modified treatment regimen, with some patients not able to obtain adequate levels of drug until manufacturing operations were restored.

\section{Insights from the CAACB study}

The CAACB study results have several implications for how biologic manufacturers approach viral contamination in producer

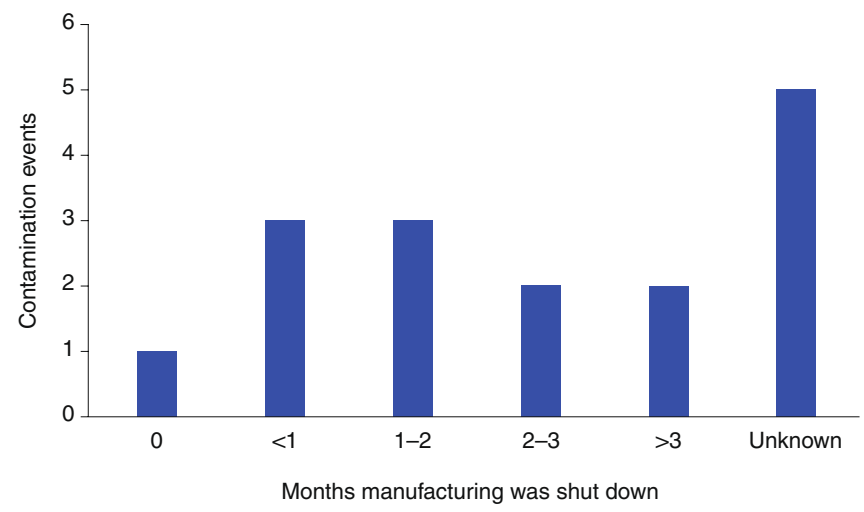

Fig. 3 | Manufacturing shut down. Months that manufacturing plants were shut down due to virus contaminations.

cell lines. Our data demonstrate that virus contaminations in cell-culture-based biopharmaceutical manufacturing are rare events when evaluated against the cumulative volume of the biotechnology 


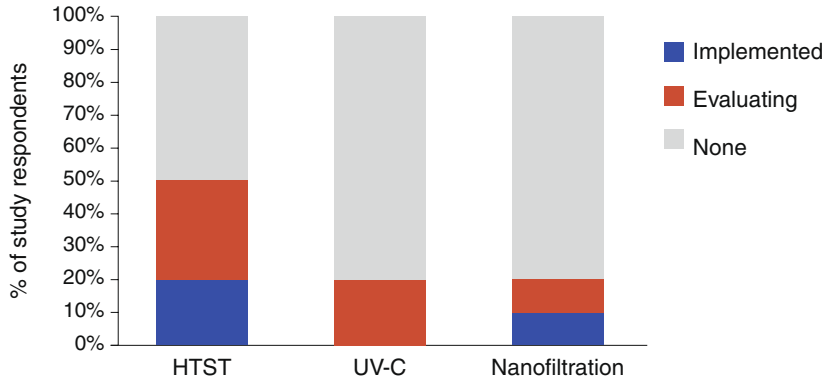

Fig. 4 | Implementing treatment of media. The percentage of respondents who have implemented (blue) or are evaluating (orange) technologies such as high-temperature, short-time (HTST) treatment, UV-C irradiation or nanofiltration to remove or inactivate potential viral contaminants from cell culture media and medium components.

industry over the past 35 years. However, our data also indicate that, on a per-company basis (of those that completed our survey), the experience is not that rare. Of the 20 companies completing the CAACB virus contamination survey, $45 \%$ of respondents reported experiencing at least one virus contamination event between 1985 and 2018, which is higher than we expected. By some estimates ${ }^{43}$, companies participating in the CAACB study comprise $>75 \%$ of global mammalian cell culture manufacturing capacity and, therefore, the risk of experiencing a virus contamination, based on total processed volume, may be expected to be higher for those companies. However, the number of contaminations reported to the CAACB per company does not correlate with total manufacturing volume, implying that a combination of circumstance, manufacturing controls in place, and prior lack of virus contamination disclosures may have contributed to this rate. These data also highlight that no manufacturer is immune from a contamination event.

Second, CHO cell cultures were contaminated by viruses different from those contaminating human or primate cell lines (Table 2). The sources of the viruses contaminating CHO cell culture and human or primate cell culture were also different. The implication is that different host cells may require the consideration and management of different virus contamination risks, with human and primate cell lines being more susceptible to contamination from operators.

Our data also provide a clear demonstration of the current limits of virus testing in ensuring viral safety. Testing bioreactor-harvest samples using the IVV assay in runs contaminated with virus was negative for virus in 4 of 14 , or $28.6 \%$ of, cases reported to the CAACB (Table 3). These false negatives are due either to the virus not replicating in the indicator cell lines chosen for the test, to viral replication not causing measurable cytopathic effect in the chosen indicator cells, or to replication of the viral isolate occurring too slowly to be detected by the end of the test. The IVV assay also takes 14 to 28 days-much too long to assess the reactor for contamination before processing downstream for purification. Therefore, several respondents implemented PCR assays as a rapid virus test before bioreactor harvest. When a viral contaminant matched a PCR target, this was effective at preventing contamination of the entire manufacturing facility. Finally, in the events reported to the $\mathrm{CAACB}$, testing raw materials was found to have limited value. In the 11 contamination events when raw materials were identified as the source of the viral contaminant, initial testing of that raw material did not detect virus. Only after the viral load was increased, through concentration or biological amplification, was the virus detected in the raw material, and then only in 3 events (Fig. 1).

Since testing has clear limitations, several companies have focused on prevention by implementing or exploring methods to remove or inactivate virus in media or components thereof. The most common technologies that have been explored in the industry include flash pasteurization (also known as high-temperature, short-time heat treatment or HTST) ${ }^{20,44,45}$, UV-C irradiation ${ }^{46}$ and nanofiltration ${ }^{47}$ (Fig. 4). Although a small sample size, to date none of the four manufacturers that has implemented HTST heat treatment to inactivate potential virus in media has experienced a contamination event after its implementation.

Finally, our data support the effectiveness of viral clearance in downstream protein purification operations (Fig. 2) for large-scale manufacturing processes. In all cases evaluated, downstream purification (for example, chromatography) and dedicated downstream viral inactivation or removal steps (for example, low-pH hold, a mixture of solvent and detergent known as solvent/detergent treatment, or nanofiltration) inactivated or removed the contaminating virus to below the limit of detection of the assay. This highlights the value, from a viral safety perspective, of downstream virus-clearance operations for the removal of potentially undetected contaminants.

\section{Implications for cell and gene therapy manufacturers}

At the end of the third quarter of 2019, >1,052 advanced therapy medicinal products (ATMPs) were being tested in phase 1-3 clinical trials (https://alliancerm.org/publication/q3-2019-data-report/), and several cell ${ }^{48}$ and gene ${ }^{49}$ therapies had received regulatory approval. Autologous cell-based products are personalized for a specific patient in critical need and are often last-line treatments. A delay in administering treatment, such as due to contamination of a production process, could negatively affect patients, possibly leading to their death. Yet practical steps to reduce the virus contamination risk are a challenge, especially for organizations that are without current institutional practices focused on viral safety and that may have limited resources. Below, we outline some of the key viral safety challenges and detail how lessons from the CAACB Virus Contamination in Biomanufacturing Study can be leveraged to ensure the safety of these emerging products.

Virus contamination risks. The three main risks for viral contamination in cell culture for therapeutic production are cell sources, materials used in cell culture, and exposure of the cell culture process stream to the operator or environment. We examine each risk in detail below.

In the case of cell sources, both recombinant biopharmaceutical products and viral vector gene therapy products have a low risk of contaminated starting cell sources as both manufacturing processes start with exhaustively characterized master cell banks. For allogeneic therapies in which cells from one donor are used to create therapies for multiple patients, the donor cells should also be characterized to assure they are virus free, per regulatory guidance. Conversely, autologous cell therapy products originate from the collection of cells from human blood or tissues each time a production process is initiated. Tests to assure that the derived cells are free of adventitious virus generally cannot be completed before initiating cell therapy manufacturing, and the process generally proceeds at risk. As previously noted, human cells are more susceptible to the replication of a variety of human viruses than are $\mathrm{CHO}$ cells (Table 2).

Cell culture processes employed for the manufacture of biopharmaceutical products and ATMP products all utilize a variety of basal medium formulations comprised of a mixture of more than 50 essential nutrients (for example, amino acids, vitamins and trace elements) and other chemicals. These are filter sterilized before use, typically with $0.1-\mu \mathrm{m}$-rated sterilizing-grade filters through which most viruses will pass. If any components of media are contaminated with virus during their manufacture or handling, they may initiate an infection during the cell culture process. Animal-derived (Table 2) and human-derived components (for example, serum and growth factors), which carry a higher risk of virus contamination 


\begin{tabular}{|c|c|c|}
\hline \multirow[t]{2}{*}{ Clearance method } & \multirow{2}{*}{$\begin{array}{l}\text { AAV } \\
\text { Size } 20 \mathrm{~nm} ; \\
\text { non-enveloped }\end{array}$} & \multirow{2}{*}{$\begin{array}{l}\text { Lentivirus } \\
\text { Size } 80-100 \mathrm{~nm} ; \\
\text { enveloped }\end{array}$} \\
\hline & & \\
\hline Heat & $\begin{array}{l}\text { Heat stable; application } \\
\text { of heat will inactivate } \\
\text { heat-sensitive viruses } \\
\text { with minimal impact } \\
\text { on AAV }\end{array}$ & $\begin{array}{l}\text { Heat sensitive; may not } \\
\text { be a suitable clearance } \\
\text { method }\end{array}$ \\
\hline Low pH & $\begin{array}{l}\text { Low-pH stable; a hold } \\
\text { at low pH will inactivate } \\
\mathrm{pH} \text {-sensitive viruses } \\
\text { with minimal impact } \\
\text { on AAV }\end{array}$ & $\begin{array}{l}\text { pH sensitive; may not } \\
\text { be a suitable clearance } \\
\text { method }\end{array}$ \\
\hline Solvent/detergent & $\begin{array}{l}\text { Non-enveloped virus; } \\
\text { detergent can be used } \\
\text { to inactivate enveloped } \\
\text { virus with minimal } \\
\text { impact on AAV }\end{array}$ & $\begin{array}{l}\text { Enveloped virus } \\
\text { sensitive to detergent; } \\
\text { not a suitable clearance } \\
\text { method }\end{array}$ \\
\hline Chromatography & $\begin{array}{l}\text { Differences in surface } \\
\text { charge can allow AAV } \\
\text { to be separated from } \\
\text { other viruses }\end{array}$ & $\begin{array}{l}\text { Differences in } \\
\text { surface charge can } \\
\text { allow lentivirus to be } \\
\text { separated from other } \\
\text { viruses }\end{array}$ \\
\hline Nanofiltration & $\begin{array}{l}\text { AAV will pass through, } \\
\text { for example, } 35-n m \\
\text { filters, allowing } \\
\text { separation of AAV from } \\
\text { larger viral contaminants }\end{array}$ & $\begin{array}{l}\text { Lentivirus will be } \\
\text { retained by nanofilters } \\
\text { (pore size, for example, } \\
35 \text { or } 50 \mathrm{~nm} \text { ), potentially } \\
\text { allowing separation } \\
\text { from smaller viral } \\
\text { contaminants }\end{array}$ \\
\hline
\end{tabular}

than other components ${ }^{50}$, are commonly added to media for ATMP production $^{51}$. With the exception of some legacy products, these components are generally not added to media for protein and vaccine manufacturing.

The final viral contamination risk is exposure of cell-culture process streams to potential virus contamination from the environment, including operators, especially during open manufacturing steps (for example, vessel transfers). For both traditional biopharmaceutical and ATMP manufacturing processes, such open processes are performed in a well-controlled environment by experienced, gowned and masked operators following aseptic procedures, yielding a so-called operationally closed process. However, due to the scale of their manufacture, ATMPs may rely much more than recombinant proteins and vaccines on open cell culture transfers. The result is an increased possibility of virus contamination from open operations for these types of products.

Virus risk-mitigation strategies. As noted above, virus-risk mitigation for biopharmaceutical manufacturing uses three complementary approaches: (i) prevention of virus entry by selecting low-risk starting and raw materials and using manufacturing controls; (ii) testing of in-process materials to ensure they are free of virus and enable lot rejection; and (iii) clearance of virus (inactivation and/ or removal) from the product ${ }^{9,14}$. Of the three, virus clearance has been shown to be of extraordinary importance in reducing the risk of virus contamination of final product (Fig. 2) ${ }^{52}$. A key question then is: can the risk mitigation approaches used for traditional biopharmaceutical manufacturing be applied to gene therapy and cell therapy manufacturing?
When considering the application of these three approaches to virus risk mitigation of ATMPs, virus clearance is the weakest link in ATMP virus safety. Many of the virus clearance unit operations used during purification of therapeutic proteins described above are not suitable for use with, or have not been widely applied to, ATMPs. If the product itself is a virus or a living cell, how will potential viral contaminants be removed or inactivated? In the case of viral vectors for gene therapy, characteristics of commonly used vectors could be exploited to provide differential clearance from many potential contaminating viruses ${ }^{53}$. Two examples of how common virus removal approaches can be used with different viral vectors are shown in Table 4. These differential clearance strategies, coupled with an understanding of the most likely viral risks, potential sources of virus, and host cell line susceptibility to those viruses, could enable the development of a virus removal strategy.

In the case of living cell-based therapies, viral clearance would be required to remove or inactivate viruses in the cell culture supernatant, as well as separating or destroying infected cells, which harbor virus, from any cells not infected with virus. To our knowledge, there is currently no technology capable of meeting this challenge. Additionally, none of the virus inactivation methods used for traditional biopharmaceutical manufacturing is compatible with the survival of living cells. Therefore, the viral safety of cell therapies currently relies solely on contamination prevention and in-process detection and lot rejection.

Contamination prevention. Viral-vectored gene therapy products utilize plasmids or recombinant viruses to initiate production ${ }^{54}$. Plasmids are generated in prokaryotic cells and should be free of viruses that would replicate in mammalian cell cultures. For recombinant viruses, master virus banks are generated and thoroughly characterized for contamination by adventitious viruses ${ }^{55}$. While it is challenging to test for adventitious viruses in the presence of recombinant viral stocks, approaches to develop successful virus tests have been developed and used ${ }^{56}$. Additionally, new detection technologies, such as high-throughput sequencing (HTS), have detected adventitious viral contaminants in the presence of virus product $^{57}$ and are being explored for use in the industry $y^{58,59}$.

Our study showed that the control of raw materials by direct testing had limited value (Fig. 1), either because virus concentrations in the raw material are below the assay detection limit or because the contaminating virus was not homogeneously distributed in the raw material. Therefore, as noted earlier, a number of biopharmaceutical manufacturers treat media before use to inactivate or remove potential viruses in raw materials (Fig. 4), and this approach should be strongly considered by manufacturers of ATMPs where feasible.

The use of animal- and human-derived raw materials during ATMP production increases viral contamination risk. When use of these materials is unavoidable, one risk-mitigation strategy is to increase the viral titer of a potential contaminant to a detectable level in a high-risk raw material through biological amplification or concentration. This enabled the detection of virus in a raw material in 3 of 11 cases, or 27\%, reported to the CAACB (Fig. 1).

Another option is treating a high-risk material to reduce contamination risk. As an example, gamma irradiation of serum has been shown to be effective against several viruses ${ }^{60}$. It is not yet standard practice for human serum, but should be strongly considered to reduce the risk of these raw materials if safer alternatives are not suitable. Despite the effectiveness of treating raw materials, we note that some animal- or human-derived materials may be sensitive to heat, radiation or UV exposure, which may ultimately affect cell growth and performance.

A better strategy, also used in the recombinant protein manufacturing industry, is to develop media that do not require animal- or human-sourced raw materials ${ }^{61}$. This can be a challenge for some 
ATMPs, especially those where nutrient requirements are not well understood, such as primary cell cultures, or which may have variable starting cells, such as autologous cell therapies.

In addition to media, ancillary materials used in the production of many cell therapy products, such as monoclonal antibodies and retrovirus vectors, will each need to be assessed individually for their virus risk to assure that they are free of adventitious virus before use in the cell-therapy manufacturing process.

Virus contamination during ATMP cell culture manufacturing processes by environmental sources must be strictly avoided. This can be done by the use of functionally closed systems, which often employ single-use, disposable equipment. If cell culture transfers cannot use closed transfer systems, they must be conducted in hoods supplied with HEPA-filtered air by appropriately gowned operators using aseptic technique. This is often more challenging in ATMP manufacturing as there are more open manipulations that provide opportunity to introduce an environmental contaminant and many small lots may be manufactured at once.

In-process testing and lot rejection. Testing for adventitious virus contamination at relevant points in the cell culture manufacturing process, usually just before production cell culture harvest, has been conducted in recombinant protein manufacture for many years. The current gold standard for lot release testing in recombinant protein products is the IVV assay, a cell-based assay that has a large breadth of detection for potential viral contaminants. However, our study demonstrated that the testing of bioreactor pre-harvest samples using the IVV assay in runs contaminated with virus was unable to detect virus in about one quarter of the cases (Table 3). An additional challenge is that the IVV assay takes between 14 and 28 days to complete ${ }^{39,56,62,63}$ and is not amenable to the rapid release required of some ATMP products. Nucleic acid-based assays, such as PCR, are faster than the IVV assay, taking less than a day. Yet PCR assays require prior knowledge of potential contaminants and only detect viral nucleic acids. HTS provides a greater breadth of detection than PCR and is seeing widespread interest from the vaccine and recombinant protein industry ${ }^{59}$. However, current HTS sample preparation approaches and bioinformatic pipelines are not as rapid as PCR and can take 7-10 days ${ }^{58}$. Additionally, determining if the contaminant identified in a nucleic acid-based assay is biologically active may require a different method, though we would note that HTS of viral RNA has been used to demonstrate a virus is biologically active ${ }^{64}$. Despite these challenges, testing should be conducted for ATMP production for samples taken before virus harvest (for viral-vectored gene therapy products) and at the end of the manufacturing process (for cell therapy products) so that if contamination with an adventitious virus is detected, informed decisions regarding product lot rejection can be made.

Because of the limitations of viral clearance for ATMPs and the short shelf lives of autologous cell therapy products, it would be prudent for companies developing ATMP manufacturing processes and analytical methods to focus on viral detection methods, such as HTS, that are rapid, broad spectrum, and more sensitive than those traditionally used.

On the basis of the lessons learned from the CAACB virus contamination project and the discussion above, it can be concluded that, at the current state of technological development, the viral safety of some ATMPs, especially autologous cell therapies, will rely almost exclusively on preventing a contamination through the use of rigorous process barriers (for example, treatment of media, reduction in the use of high-risk materials, testing of high-risk materials that cannot be eliminated from use or treated to reduce risk, and closed manufacturing systems). In-process virus testing, particularly for autologous cell therapies, has clear limitations. Current approaches cannot provide both broad-spectrum detection and rapid results. Despite this, appropriate virus detection assays should be added to the current safety testing done on each lot. Final test results would likely come after an autologous cell therapy treatment had begun but would enable informed patient treatment decisions should a virus contaminant be detected or suspected. In summary, virus control efforts for organizations developing and operating ATMP manufacturing processes should focus primarily on methods to prevent virus contamination in the first place, although we would note that best practices may change as new technologies are developed to meet current challenges in testing and viral clearance for ATMPs.

\section{Conclusions}

The biotechnology industry has a long history of supplying safe and effective therapies to patients owing to the extensive controls in place to ensure product safety. Despite these controls, viral infection of cell culture is a real risk with severe consequences. Learning from these events has historically been a challenge; the work presented here represents a comprehensive collection and analysis of previously unpublished industry-wide viral contamination information. The CAACB study has identified five viruses that have been shown to contaminate $\mathrm{CHO}$ cell culture and four viruses that have contaminated cell culture of human or primate cells. Importantly, the viruses that have been shown to contaminate human or primate cell lines can also infect humans. The choice of which cell line to use for recombinant protein or vaccine production is a complicated decision, of which viral contamination risks are just one consideration. However, manufacturers that are using human or primate cells should be aware of the difference in the potential risk to patients from a viral contaminant in products produced in those cells compared with $\mathrm{CHO}$ cells.

Although testing is a key component of viral safety in biotechnology products, the data presented here indicate that testing alone is not enough to ensure that a given product is free of a viral contaminant, and that a holistic, multifaceted approach must be taken. This is never more true than when faced with a previously unknown emerging virus, such as SARS-CoV-2, where the capacity of the virus to infect production cell lines or be detected in existing assays is not initially known. Some approaches, such as the implementation of rapid PCR tests for forward processing decisions, have been shown to enhance containment and prevent the spread of a contaminating virus to other parts of the manufacturing facility. We believe that collective effort and shared knowledge can ensure the continued success of the life-saving therapies of today and tomorrow.

Finally, lessons from the CAACB study, applied to emerging biotech products, lead us to conclude that the viral safety of some ATMPs rely almost exclusively on preventing contamination through the use of rigorous process controls. Further, the short time frame associated with the use of many ATMPs, relative to their manufacture, is a challenge for current viral testing paradigms and offers a clear opportunity for technological advancement.

Received: 4 April 2018; Accepted: 1 April 2020; Published online: 27 April 2020

\section{References}

1. Merten, O. W. Virus contaminations of cell cultures - a biotechnological view. Cytotechnology 39, 91-116 (2002).

2. Sawyer, W. A. et al. Jaundice in army personnel in the western region of the United States and its relation to vaccination against yellow fever: Part I. Am. J. Epidemiol. 39, 337-430 (1944).

3. Shah, K. \& Nathanson, N. Human exposure to SV40: review and comment. Am. J. Epidemiol. 103, 1-12 (1976).

4. Stratton, K., Alamario, D. A. \& McCormick, M. C. Immunization Safety Review: SV40 Contamination of Polio Vaccine and Cancer. (National Academies Press, Washington, DC, 2003). 
5. Rosendaal, F. R., Smit, C. \& Briët, E. Hemophilia treatment in historical perspective: a review of medical and social developments. Ann. Hematol. 62, 5-15 (1991).

6. Weinberg, P. D. et al. Legal, financial, and public health consequences of HIV contamination of blood and blood products in the 1980s and 1990s. Ann. Intern. Med. 136, 312-319 (2002).

7. Butler, D. Petition prompts backlash against scientists. Nature 367, 304 (1994).

8. Barker, S. \& Swinbanks, D. Health ministry accepts liability in Japanese HIV-infected blood row. Nature 379, 663-664 (1996).

9. International Council for Harmonisation of Technical Requirements for Pharmaceuticals for Human Use. Q5A(R1). Viral Safety Evaluation Of Biotechnology Products Derived From Cell Lines Of Human Or Animal Origin (International Council for Harmonisation of Technical Requirements for Pharmaceuticals for Human Use, 1999).

10. Suomela, H. Inactivation of viruses in blood and plasma products. Transfus Med. Rev. 7, 42-57 (1993).

11. Burnouf, T. Modern plasma fractionation. Transfus. Med. Rev. 21 101-117 (2007).

12. Walsh, G. Biopharmaceutical benchmarks 2014. Nat. Biotechnol. 32, 992-1000 (2014).

13. Grillberger, L., Kreil, T. R., Nasr, S. \& Reiter, M. Emerging trends in plasma-free manufacturing of recombinant protein therapeutics expressed in mammalian cells. Biotechnol. J. 4, 186-201 (2009).

14. Kozlowski, S. \& Swann, P. Current and future issues in the manufacturing and development of monoclonal antibodies. Adv. Drug Deliv. Rev. 58, 707-722 (2006).

15. Liu, S. et al. Development and qualification of a novel virus removal filter for cell culture applications. Biotechnol. Prog. 16, 425-434 (2000).

16. Bethencourt, V. Virus stalls Genzyme plant. Nat. Biotechnol. 27, 681 (2009).

17. Allison, M. As Genzyme flounders, competitors and activist investors swoop in. Nat. Biotechnol. 28, 3-4 (2010).

18. Burstyn, D. G. Contamination of genetically engineered Chinese hamster ovary cells. Dev. Biol. Stand. 88, 199-203 (1996).

19. Rabenau, H. et al. Contamination of genetically engineered $\mathrm{CHO}$-cells by epizootic haemorrhagic disease virus (EHDV). Biologicals 21, 207-214 (1993).

20. Garnick, R. L. Experience with viral contamination in cell culture. Dev. Biol. Stand. 88, 49-56 (1996).

21. Garnick, R. L. Raw materials as a source of contamination in large-scale cell culture. Dev. Biol. Stand. 93, 21-29 (1998).

22. Kiss, R. D. Practicing safe cell culture: applied process designs for minimizing virus contamination risk. PDA J. Pharm. Sci. Technol. 65, 715-729 (2011).

23. Ault, A. US FDA again stops urokinase sales. Lancet 354, 310 (1999).

24. Oehmig, A. et al. Identification of a calicivirus isolate of unknown origin. J. Gen. Virol. 84, 2837-2845 (2003)

25. Nims, R.W. et al. Detection of Cache Valley virus in biologics manufactured in CHO cells. Biopharm. Int. 21, 89-95 (2008).

26. Rubino, M. J. Experiences with HEK293: a human cell line. PDA J. Pharm. Sci. Technol. 64, 392-395 (2010).

27. Plavsic, M. et al. Caliciviridae and vesivirus 2117. Bioprocess. J. 9, 6-12 (2011).

28. Plavsic, M., Shick, K., Bergmann, K. F. \& Mallet, L. Vesivirus 2117: cell line infectivity range and effectiveness of amplification of a potential adventitious agent in cell culture used for biological production. Biologicals 44, 540-545 (2016).

29. Qiu, Y. et al. Identification and quantitation of vesivirus 2117 particles in bioreactor fluids from infected Chinese hamster ovary cell cultures. Biotechnol. Bioeng. 110, 1342-1353 (2013).

30. Moody, M., Alves, W., Varghese, J. \& Khan, F. Mouse minute virus (MMV) contamination - a case study: detection, root cause determination, and corrective actions. PDA J. Pharm. Sci. Technol. 65, 580-588 (2011).

31. Baylis, S. A., Finsterbusch, T., Bannert, N., Blümel, J. \& Mankertz, A. Analysis of porcine circovirus type 1 detected in Rotarix vaccine. Vaccine 29, 690-697 (2011).

32. McClenahan, S. D., Krause, P. R. \& Uhlenhaut, C. Molecular and infectivity studies of porcine circovirus in vaccines. Vaccine 29, 4745-4753 (2011).

33. Besselsen, D. G. et al. Molecular characterization of newly recognized rodent parvoviruses. J. Gen. Virol. 77, 899-911 (1996).

34. Nims, R. W. Detection of adventitious viruses in biologicals-a rare occurrence. Dev. Biol. (Basel) 123, 153-164; discussion 183-197 (2006).

35. Willkommen, H. et al. Meeting report: 2013 PDA Virus \& TSE Safety Forum. PDA J. Pharm. Sci. Technol. 68, 193-214 (2014).

36. Anonymous. A united front. Nature 472, 389-390 (2011).

37. Campbell, G. L. et al. Second human case of Cache Valley virus disease. Emerg. Infect. Dis. 12, 854-856 (2006).

38. Sexton, D. J. et al. Life-threatening Cache Valley virus infection. N. Engl. J. Med. 336, 547-549 (1997).
39. Gombold, J. et al. Systematic evaluation of in vitro and in vivo adventitious virus assays for the detection of viral contamination of cell banks and biological products. Vaccine 32, 2916-2926 (2014).

40. International Society for Pharmaceutical Engineering. Baseline Guide Volume 6: Biopharmaceutical Manufacturing Facilities (International Society for Pharmaceutical Engineering, 2013)

41. Brorson, K. et al. Current and future approaches to ensure the viral safety of biopharmaceuticals. Dev. Biol. (Basel) 118, 17-29 (2004).

42. Farshid, M., Taffs, R. E., Scott, D., Asher, D. M. \& Brorson, K. The clearance of viruses and transmissible spongiform encephalopathy agents from biologicals. Curr. Opin. Biotechnol. 16, 561-567 (2005).

43. Anonymous. The 2019 16th Annual Report and Survey of Biopharmaceutical Manufacturing Capacity and Production (BioPlan Associates, Rockville, MD, USA, 2019).

44. Schleh, M. et al. Susceptibility of mouse minute virus to inactivation by heat in two cell culture media types. Biotechnol. Prog. 25, 854-860 (2009).

45. Murphy, M., Quesada, G. M. \& Chen, D. Effectiveness of mouse minute virus inactivation by high temperature short time treatment technology: a statistical assessment. Biologicals 39, 438-443 (2011).

46. Meunier, S. M., Sasges, M. R. \& Aucoin, M. G. Evaluating ultraviolet sensitivity of adventitious agents in biopharmaceutical manufacturing. J. Ind. Microbiol. Biotechnol. 44, 893-909 (2017).

47. Mundt, W. et al. Virus filtration of cell culture media. Patent WO2013192009A1 (2003).

48. Mullard, A. Second anticancer CAR T therapy receives FDA approval. Nat. Rev. Drug Discov. 16, 818 (2017).

49. Anonymous. FDA approves hereditary blindness gene therapy. Nat. Biotechnol. 36, 6 (2018).

50. Mahmood, A. \& Ali, S. Microbial and viral contamination of animal and stem cell cultures: common contaminants, detection and elimination. J. Stem Cell Res. Ther. 2, 149-155 (2017).

51. Brindley, D. A. et al. Peak serum: implications of serum supply for cell therapy manufacturing. Regen. Med. 7, 7-13 (2012).

52. Shukla, A. A. \& Aranha, H. Viral clearance for biopharmaceutical downstream processes. Pharm. Bioprocess. 3, 127-138 (2015).

53. Ye, G. J. et al. Herpes simplex virus clearance during purification of a recombinant adeno-associated virus serotype 1 vector. Hum. Gene Ther. Clin. Dev. 25, 212-217 (2014).

54. Wirth, T., Parker, N. \& Ylä-Herttuala, S. History of gene therapy. Gene 525, 162-169 (2013)

55. US Food and Drug Administration. Draft Guidance for Industry: Chemistry, Manufacturing, and Control (CMC) Information for Human Gene Therapy Investigational New Drug Applications (INDs) (US Food and Drug Administration, 2018).

56. US Food and Drug Administration. Guidance for Industry: Characterization and Qualification of Cell Substrates and Other Biological Materials Used in the Production of Viral Vaccines for Infectious Disease Indications (US Food and Drug Administration, 2010).

57. Victoria, J. G. et al. Viral nucleic acids in live-attenuated vaccines: detection of minority variants and an adventitious virus. J. Virol. 84, 6033-6040 (2010).

58. Khan, A. S. et al. A multicenter study to evaluate the performance of high-throughput sequencing for virus detection. mSphere $\mathbf{2}$, e00307-17 (2017).

59. Khan, A. S. et al. Advanced virus detection technologies interest group (AVDTIG): Efforts on high throughput sequencing (HTS) for virus detection PDA J. Pharm. Sci. Technol. 70, 591-595 (2016).

60. Gauvin, G. \& Nims, R. Gamma-irradiation of serum for the inactivation of adventitious contaminants. PDA J. Pharm. Sci. Technol. 64, 432-435 (2010).

61. Miki, H. \& Takagi, M. Design of serum-free medium for suspension culture of $\mathrm{CHO}$ cells on the basis of general commercial media. Cytotechnology 67, 689-697 (2015)

62. US Food and Drug Administration. Points to Consider in the Characterization of Cell Lines Used to Produce Biologicals (US Food and Drug Administration, 1993).

63. World Health Organization. Requirements for the use of animal cells as in vitro substrates for the production of biologicals. in WHO Expert Committee on Biological Standardization, 47th Report (World Health Organization, 1998).

64. Brussel, A. et al. Use of a new RNA next generation sequencing approach for the specific detection of virus infection in cells. Biologicals 59, 29-36 (2019).

\section{Acknowledgements}

The authors would like to acknowledge the support of the members of the Consortium on Adventitious Agent Contamination in Biomanufacturing (CAACB). CAACB members, past and present, include Amgen, Asahi Kasei Bioprocess, AstraZeneca, Biogen, BioMarin, Boehringer Ingelheim, Brammer Bio, Bristol-Myers Squibb, Charles River Labs, CSL Behring, Eli Lilly and Co., EMD Serono, Genentech, Gritstone Oncology, Histogenics, LFB, Merck \& Co., Merrimack Pharmaceuticals, MilliporeSigma, 
Novartis, Pall Corporation, Pfizer, Regeneron, Sanofi, Sanofi Genzyme, Sanofi Pasteur, Takeda and Thermo Fisher.

\section{Competing interests}

P.W.B., M.E.W., J.C.L., I.T.M.H., F.J.K., J.W., A.J.S. and S.L.S. performed the research at the Massachusetts Institute of Technology with funding from CAACB member companies; J.B., A.B., D.C., M.C., H.D., L.G., J.G., D.G., R.K., T.R.K., R.L., Y.L., J.M., L.M., C.M., M. Moody, S.M., M. Murphy, M.P., N.J.R., D.R., M.R., R. Schicho, R. Snyder, D.S. and C.Z. were employees of CAACB member companies while engaged in the reported research.

\section{Additional information}

Supplementary information is available for this paper at https://doi.org/10.1038/ s41587-020-0507-2.

Correspondence should be addressed to S.L.S.

Reprints and permissions information is available at www.nature.com/reprints.

Publisher's note Springer Nature remains neutral with regard to jurisdictional claims in published maps and institutional affiliations.

(c) The Author(s), under exclusive licence to Springer Nature America, Inc. 2020 